\title{
Microbial mutagenesis by atmospheric and room-temperature plasma (ARTP): the latest development
}

\author{
Christoph Ottenheim ${ }^{1}$, Margarete Nawrath ${ }^{1,2}$ and Jin Chuan Wu${ }^{1 *}$
}

\begin{abstract}
Although rational genetic engineering is nowadays the favored method for microbial strain improvement, random mutagenesis is still in many cases the only option. Atmospheric and room-temperature plasma (ARTP) is a newly developed whole-cell mutagenesis tool based on radio-frequency atmospheric-pressure glow discharge plasma which features higher mutation rates than UV radiation or chemical mutagens while maintaining low treatment temperatures. It has been successfully applied on at least 24 bacterial and 14 fungal species, but also on plants, dinoflagellates, and other microbial communities for the improvement of tolerance to medium components, to increase cellular growth and production of cellular biomass, to enhance enzyme activity, and to increase the production of various chemicals. Achievements like $385.7 \%$ of acetic acid production enhancement in Acetobacter pasteurianus give this new mutagenesis tool a promising future. However, certain questions remain regarding optimal operational conditions, the effects at subcellular levels, and standard operation procedures, which need to be addressed to facilitate applications of ARTP in microbial breeding and other fields such as evolution of enzymes.
\end{abstract}

Keywords: Random mutagenesis, Atmospheric and room-temperature plasma, Mutation mechanism, Strain breeding, Industrial application

\section{Introduction}

Genetic enhancement of whole-cell systems is of great interest in microbial biotechnology. Rational design in genetic engineering has become during the last decades the preferred method of choice with the CRISPR/Cas9 system being the most recent advance (Barrangou and Horvath 2017). However, random mutagenesis is still in many cases the only feasible approach, for instance, if the corresponding genomic locus to the desired phenotype is unknown or if a complex genetic regulation is underlying. Random mutagenesis is also superior from a commercial standpoint as altered strains are classified as genetically unmodified which requires no attention to legal regulations. Besides, products labeled as "GMO free" are currently much better accepted by the public (Twardowski and Małyska 2015).

\footnotetext{
*Correspondence: wu_jinchuan@ices.a-star.edu.sg

${ }^{1}$ Institute of Chemical and Engineering Sciences, Agency for Sciences, Technology and Research (A*STAR), 1 Pesek Road, Singapore 627833, Singapore

Full list of author information is available at the end of the article
}

Although random mutagenesis can be done biologically using methods like proofreading-deficient polymerase (Kim et al. 2013), it is typically achieved by application of chemical mutagens like alkylating agents (Lackmann and Bandow 2014) or azides (Yolmeh and Khomeiri 2017) and physical mutagens like conventional radiations (Yolmeh and Khomeiri 2017) or heavy particle beams (Lackmann and Bandow 2014). The induced DNA damages are subsequently repaired by the SOS system leading to DNA alterations (Bridges 2001). However, almost all tools for random mutagenesis are to a certain extent risky to handle. Whereas chemical mutagens expose the user to high (e.g., ethyl methanesulfonate and methylnitronitrosoguanidine) or very high toxicity (e.g., ethidium bromide and sodium azide), radiation (e.g., X-ray and $\gamma$-ray) exposes the user to a permanent danger which requires additional control measures such as radiation badges and radiation barriers. In addition, the generation of radiation requires often bulky and expensive equipment, specialized knowledge for operation and additional security measures to restrict access. 
Physical plasmas are fully or partially ionized gases which are consisting of neutral and charged particles. They are generally classified into high- and low-temperature plasmas with variations in working gas (e.g., helium, argon, nitrogen, and oxygen), pressure (0.1 Pa up to atmospheric pressure), electromagnetic field, discharge configuration, and temporal behaviors (Bogaerts et al. 2002). Radio-frequency atmospheric-pressure glow discharge plasma (RF APGD) is one of the cold atmospheric plasmas of increased interest which can be produced in between two electrodes driven by a radio-frequency power supply at atmospheric pressure (Tendero et al. 2006). Room-temperature plasma received first attention in applied research for its possible use as a sterilization method for heat-sensitive surfaces (Kramer et al. 2015). However, the sub-lethal treatment suggested also a possible application in the field of mutagenesis. In a quantitative approach using flow cytometry analysis based on the $u m u$ test, the ARTP system showed greater DNA damage with higher mutation rates than UV radiation or the application of two selected chemical mutagens (Zhang et al. 2015c). After initial studies proved the successful application of RF APGD plasma jets in microbial breeding (Wang et al. 2010), an atmospheric and roomtemperature plasma mutation system (ARTP) was constructed and made commercially available. The ARTP system requires helium (>99.99\%) as a working gas and a typical electric socket as a power source. With a weight of $100 \mathrm{~kg}$ and a size of $33 \mathrm{~cm} \times 33 \mathrm{~cm} \times 33 \mathrm{~cm}$, it is of manageable dimensions, requires minimal training, and produces no hazardous radiation, toxic chemicals, or any environmentally harmful waste.

Here, we summarize the progress of ARTP-induced mutagenesis with focus on the most recent reports since the last review (Zhang et al. 2014) and the progress in understanding the underlying mechanisms. In the first parts, we elucidate the technical and physico-chemical background in a comprehensive manner. Following this, we focus in the second part on the description and extensive review of the technical parameters and the combination of the ARTP with other mutagenesis methods to enable ARTP operators to understand and optimize the process. Subsequently, a summary of the biotechnological applications is given in the third part. Finally, we close with the concluding remarks to reveal knowledge gaps and future prospects.

\section{Technical and physico-chemical background of ARTP}

The ARTP mutagenesis system was initially invented by the Department of Chemical Engineering of Tsinghua University and commercialized by Si Qing Yuan
Biotechnology (now Tmax Tree Co., Ltd.) with a vertically mounted RF APGD plasma jet generator as the core component (Fig. 1a) (Zhang et al. 2014). It is currently the only commercially available system and its distribution has been mainly restricted to its origin China. Inside the ARTP apparatus, helium is ionized by a radio-frequency electric field and blown through a nozzle onto a microbial sample on a metal plate fixed to an adjustable platform. The use of atmospheric-pressure plasma in this setup removes the necessity of an expensive vacuum system. Due to the low breakdown voltage, the plasma maintains discharge uniformity, generates little amounts of UV radiation, and assures, in combination with the cooling of the cathode, a biologically compatible gas temperature. A continuous gas flow ensures little mixing with the surrounding air which minimizes the generation of germicidal ozone.

The exact cause of mutagenesis by physical plasma has not yet been fully clarified, but various experiments were carried out on isolated DNA and on DNA in vivo. Besides $\mathrm{UV}$ radiation, the generation of reactive chemical species was identified as the most probable cause (Li et al. 2008). Experiments on isolated plasmid DNA showed a fast degradation after RF APGD helium plasma treatment with damage severity depending on the plasma-generating conditions ( $\mathrm{Li}$ et al. 2008). However, DNA in vivo is also protected by other biomolecules shielding the DNA from damages caused by oxidative stress. Systems like the SOS repair system in prokaryotes are aiding the damaged DNA to maintain its integrity while possibly introducing mutations. In this manner, genes involved in the SOS DNA repair system and genes that are known to respond to oxidative stress were found to be activated in response to physical plasma (Winter et al. 2013). Besides those direct interactions between reactive chemical species and DNA, also indirect reactions with other biomolecules and reactive chemical species leading to mutagenic products were suggested as possible causes for DNA base alterations and the induction of single- or doublestrand breaks (Arjunan et al. 2015). While the impact of plasma on DNA is straightforward, the influence of plasma composition and the resulting critical treatment severity is more complex. The amount of UV radiation and the composition of the generated reactive chemical species depends mainly on the employed gases. While noble gases like argon or helium are generating less UV radiation, the addition of nitrogen or oxygen to noble gases increases the amount of reactive chemical species. Hydroxyl radicals $(\cdot \mathrm{OH})$, atomic oxygen $(\mathrm{O})$, ozone $\left(\mathrm{O}_{3}\right)$, and superoxide anions $\left(\mathrm{O}_{2}^{--}\right)$are the most frequently produced reactive chemical species. Furthermore, especially in contact with aqueous solutions, nitrous acid 


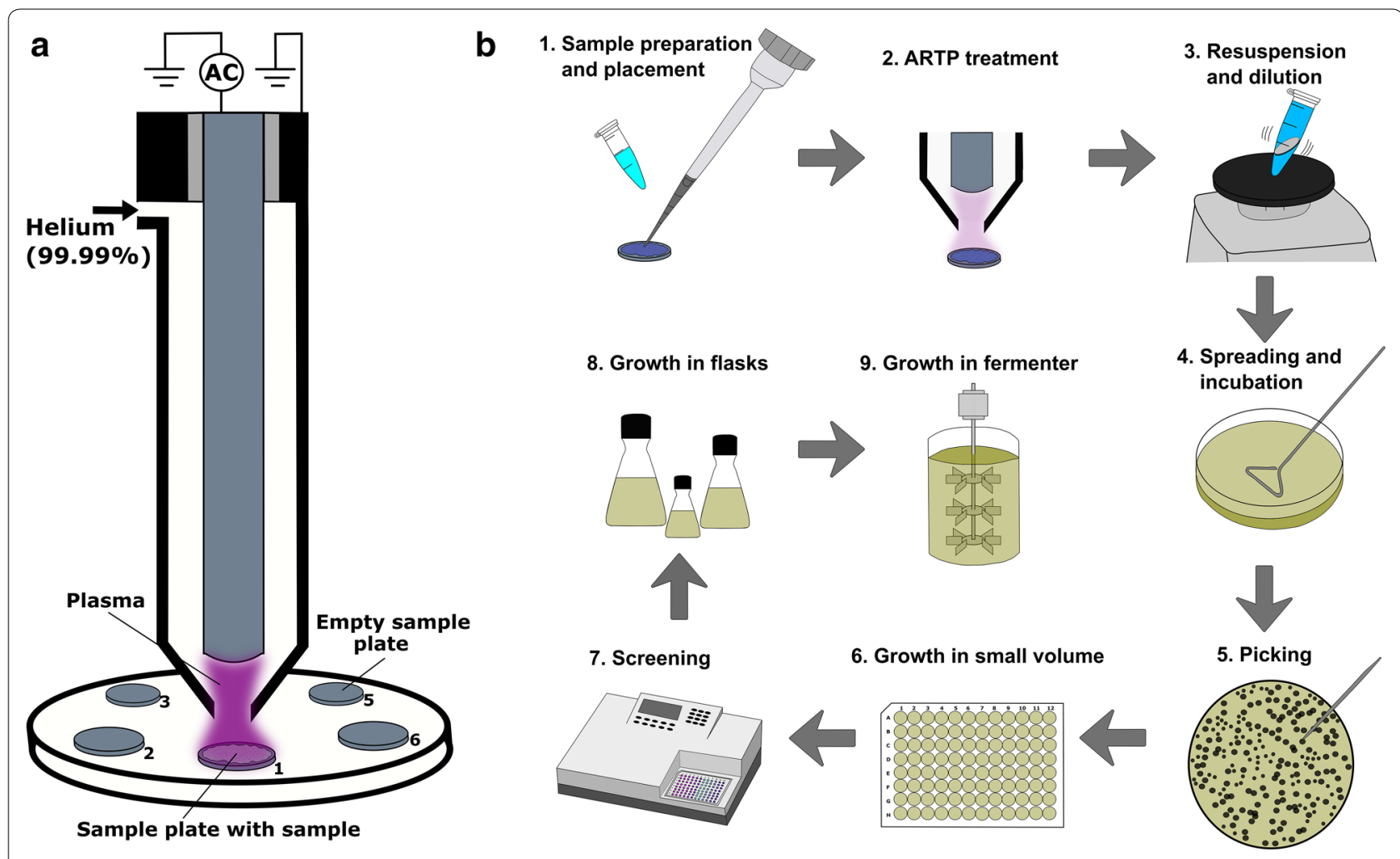

Fig. 1 a RF APGD plasma jet generator as the core component of the ARTP system treating a microbial sample (adapted from Zhang et al. 2014). b Typical sequence of an ARTP mutagenesis workflow

$\left(\mathrm{HNO}_{2}\right)$, nitric acid $\left(\mathrm{HNO}_{3}\right)$, hydroxide anions $\left(\mathrm{OH}^{-}\right)$, and hydrogen peroxide $\left(\mathrm{H}_{2} \mathrm{O}_{2}\right)$ are produced (Lackmann and Bandow 2014). When using helium as a working gas, helium metastables $\left(\mathrm{He}^{*}, \mathrm{He}_{2}^{*}\right)$, helium ions $\left(\mathrm{He}^{+}, \mathrm{He}_{2}{ }^{+}\right)$, and nitrogen molecular ions $\left(\mathrm{N}_{2}^{+}\right)$were additionally identified (Wang et al. 2012). Maintaining microbial cell functionality and integrity is required to pass on random mutations to the next generation. However, a high plasma treatment severity can cause irreparable damages to DNA, proteins, and the whole cell, therefore, requiring careful adjustment of the plasma-generating parameters. Enzyme inactivation was suggested to be mainly caused by a degradation of chemical groups, oxidation of catalytic centers, and the overall destruction of the secondary structure (Misra et al. 2016). Direct exposure to room-temperature plasma resulted also in the removal of extracellular matrix followed by etching of whole cells as shown by scanning electron microscopy (Lackmann et al. 2013). Cell etching was monitored in another study by atomic force microscopy. Extended plasma treatment eventually led to a rupture of the cell wall. In both studies, UV treatment alone did not lead to an extended damage of the cell wall (Pompl et al. 2009) which only left reactive chemical species as the primary cause.

\section{Technical parameters}

Experimental workflow

The ARTP system was designed to allow easy adaptation to different microorganisms. Therefore, a large range of parameter combinations are possible. However, not all possible parameter combinations lead to biologically compatible plasma treatment conditions. The typical workflow (Fig. 1b) starts with the preparation of a defined suspension of microorganisms followed by the ARTP treatment. Subsequently, the treated microorganisms are re-suspended, adequately diluted, and streaked out on agar plates to yield single colonies. The colonies are then screened according to the targeted phenotypes (e.g., photometric test). However, due to the multitude of parameter combinations, it can be challenging to identify optimal plasma mutation conditions leading to single, isolated colonies under maximal usage of the agar surface. Overall, the following three categories are of importance. First, there are the intrinsic but variable parameters of the ARTP system such as the helium gas flow rate (standard liter per minute, SLPM), the gap space between nozzle and sample plate (millimeter, $\mathrm{mm}$ ), the energy input (Watt, W), and the treatment time (seconds, s). Second, the sample itself causes variations 
through the kind of microorganism to be manipulated, the cell/spore concentration, the used suspension liquid, and its volume. Third, the subsequent post-treatment of the sample after plasma treatment including the resuspension liquid and time, the subsequent dilution, and the volume used for spreading on agar.

\section{ARTP system variables}

For the mutagenesis of biological samples, the ARTP manufacturer suggests standard values for each adjustable parameter to achieve biologically compatible conditions and the generation of reactive chemical species. In compliance with the suggested conditions, a high density of electrons and metastable helium $\left(\mathrm{He}^{*}, \mathrm{He}_{2}{ }^{*}\right)$, $\mathrm{He}^{+}, \mathrm{He}_{2}{ }^{+}$and $\mathrm{N}_{2}{ }^{+}$are generated (Zhang et al. 2014). A helium gas flow rate of 10 SLPM or higher is suggested to avoid interference between the plasma jet and surrounding air as this leads to the formation of germicidal ozone. However, in a prior study, a positive correlation between gas flow rate and the reactive chemical species concentration was shown by the increased damage after treatment of isolated plasmid DNA with plasma generated at flow rates between 5 and 30 SLPM. A $2 \mathrm{~mm}$ distance between sample and nozzle is recommended. Larger distances were shown to decrease the concentration of reactive chemical species as shown by the decreased damage severity with distances between 2 and $10 \mathrm{~mm}$. An energy input of around $120 \mathrm{~W}$ is suggested to be used. The energy input was found to be positively correlated with the generation of reactive chemical species as proven earlier by damage severity of plasmid DNA treated with plasma between 10 and $120 \mathrm{~W}$ (Li et al. 2008). However, increased energy input leads also to a rise in temperature which is especially of significance for the survival of the whole cells. Within an energy input of 40-200 W, temperature was found to be within a biologically compatible range between 36 and $57^{\circ} \mathrm{C}$ (Zhang et al. 2014). The last intrinsic parameter of the ARTP system and the most important parameter for each experimental setup is the treatment time. It is primarily used to determine the dose of the reactive chemical species to the microorganism under selected conditions. Direct treatment of isolated DNA under identical plasma-generating conditions with time variations between 0.5 to $10 \mathrm{~min}$ was shown to increase DNA damages ( $\mathrm{Li}$ et al. 2008). However, it can be assumed that due to the high complexity and the presence of more sensitive molecules, the effective treatment time for whole cells is situated at a shorter exposure time. Summarizing the applied values of the operational parameters in the literature, a high variety from the suggested standard values is present. However, as some studies do not report their parameter values, a representative distribution cannot be derived. A wide variation of the helium gas flow rate can be found. While many studies selected the suggested helium gas flow rate of 10 SLPM, an equal number of studies reported a helium gas flow rate of 15 SLPM. Single studies went as low as 2 SLPM (Zong et al. 2012; Ren et al. 2017). The suggested distance between sample and nozzle of $2 \mathrm{~mm}$ was used in almost all reports. Single cases reported a further distance of $1 \mathrm{~cm}$ (Zong et al. 2012; Li et al. 2014). The energy input is a critical parameter due to its ability of heating the sample to undesirable temperatures. In the reviewed studies, the energy input was, as suggested, typically at 100 or $120 \mathrm{~W}$. One single study chose a low-energy input of $40 \mathrm{~W}$ which might explain the extended required treatment time ( $\mathrm{Li}$ et al. 2014). Three studies applied $180 \mathrm{~W}$ either for spores or filamentous fungi which are expectably less affected by higher temperatures due to their higher resistance (Xu et al. 2011, 2012; Wang et al. 2016a). Treatment time is used as the main parameter to adjust the exposure of the sample to plasma while keeping all other parameters constant. Therefore, the treatment time in the reviewed studies is mainly dependent on the other parameters preset. When other parameters were chosen to generate less reactive chemical species, this resulted in the requirement to select a longer treatment time. However, the exact impact of a single parameter cannot be estimated as in most studies multiple parameters were significantly changed and no systematic approaches were applied.

\section{Sample-related variables}

The kind of microorganism (e.g., species, Gram-positive/ Gram-negative) and its current developmental stage (e.g., viable cell or spore) were shown to be of significance in case of plasma sterilization. For the ARTP, the treatment time under otherwise constant operation parameters should be evaluated for each strain by establishing a death rate curve. The suggested range for the death rate curve for bacteria is in general estimated to be effective in a range between 15 and $120 \mathrm{~s}$, for Actinomycetes between 30 and $180 \mathrm{~s}$, for fungi between 60 and $360 \mathrm{~s}$, for yeasts between 30 and $240 \mathrm{~s}$, and for microalgae between 5 and $150 \mathrm{~s}$. However, as no research involving the systematic sub-lethal, helium-based plasma treatment of microorganisms via ARTP has been conducted yet, only the current findings regarding plasma sterilization combined with the time suggestions mentioned above can give a general indication for ARTP mutagenesis. Sterilization studies for different species involving Gram-positive and Gram-negative microorganisms either concluded a greater resistance of Gram-positive microorganisms or no difference at all. A study investigated the survival after plasma treatment of the Gram-negative Escherichia coli, the Gram-positive Staphylococcus aureus, the yeast Saccharomyces cerevisiae, and Bacillus subtilis spores using 
helium/oxygen as a working gas. While $\mathrm{D}$ values for $E$. coli and S. aureus were similar to 18 and 19 s, respectively, S. cerevisiae showed with $115 \mathrm{~s}$ and B. subtilis spores with $840 \mathrm{~s}$, a much higher resistance to the plasma treatment (Lee et al. 2006). In another sterilization study with argon plasma involving 11 different bacterial strains, susceptibility of Gram-negative species was demonstrated to be generally greater than that of Gram-positive species. However, the susceptibility of Gram-positive species was determined to be strain specific (Ermolaeva et al. 2011). On contrary, two E. coli strains and one Listeria monocytogenes strain were exposed to dielectric barrier discharge atmospheric cold plasma with a variety of working gas mixtures containing $\mathrm{O}_{2}, \mathrm{~N}_{2}$, and $\mathrm{CO}_{2}$. The Gram-positive $L$. monocytogenes was inactivated more rapidly than the Gram-negative E. coli strains and a difference in inactivation time between the E. coli strains was found ( $\mathrm{Lu}$ et al. 2014). These inconclusive findings can be reasoned by variations in plasma generation, but might also elaborate a strain specificity rather than the Gram classification. However, while fungi exhibited a greater resistance than bacteria, spores have clearly the greatest resistance against plasma treatment. For the preparation of appropriate cell concentrations for the ARTP treatment, it is suggested to harvest cells or spores from a culture during the logarithmic phase and wash 2-3 times with sterile solution. Subsequently, the resulting $\mathrm{OD}_{600}$ should be adjusted to $0.6-0.8$ or to $10^{6}-10^{8}$ cells $\times \mathrm{ml}^{-1}$. It must be emphasized that the optical density can only give a rough indication of the cell concentration and is heavily dependent on strain, cell type, and growth media. A cell count would be only possible in case of non-motile cells. Therefore, it would be instead advisable to use a constant, appropriate, and high optical density under consideration of the subsequent dilution steps with the aim to obtain single colonies on the final agar plate. The suspension liquid itself is only recommended to be sterile while the volume transferred to the sample plate should be in the range of 10-20 $\mu \mathrm{l}$. In case of extended treatment times or small volumes, an addition of $5 \%$ glycerol to the suspension liquid is suggested to minimize sample evaporation. One study investigated the impact of suspension composition on the severity of the plasma treatment. DNA samples were suspended after plasma treatment in water, phosphate-buffered saline (PBS), and media which consisted of carbonate buffer, salts, amino acids, phenol indicator, and vitamins. While water did not protect the sample, a minimal protection through PBS was observed. In contrast, the media protected the DNA sample to a large extent (Leduc et al. 2009). A later study detected a similar degree of DNA damage in PBS and aqueous solution; however, the formation of strand breaks in supercoiled DNA was slower in PBS than in water. In contrast, a tris-EDTA buffer prevented DNA damages greatly (O'Connell et al. 2011). These findings can be attributed to the buffer itself and to additional compounds within the buffer acting as radical scavengers. Furthermore, the effects of certain parameters interacting with each other should not be neglected. Besides the already mentioned energy input which leads to a temperature rise and subsequently to reduced cell viability, especially the energy input and the helium gas flow rate but also the chosen suspension liquid leads to an increased evaporation. This results in a change of the initial conditions like buffer and cell concentration and changes the overall experimental setup. For sample-related variables, only limited conclusions from the available studies can be drawn as most factors are estimated to exhibit weaker effects than the earlier mentioned ARTP system variables. The microorganism and its current state of development were found to have a strong impact. Fungal species tend to be more resilient than bacterial species and dormant bodies such as spores exhibited the highest resistance to ARTP plasma treatment. However, no conclusions about differences between Gram-positive and Gram-negative species or even amongst strains of the same species can be drawn. For most studies, cell concentration was adjusted to the suggested $\mathrm{OD}_{600}$ of 1 and 1.5 (Sun et al. 2015) or even 2 (Lu et al. 2011). As suspension liquid, a physiological saline was mainly employed followed by $50 \mathrm{mM}$ PBS buffer at $\mathrm{pH} 6$ or 7 . In a single study $10 \%$, glycerol was used (Wang et al. 2016c). Mostly, the suggestion of applying a volume of 10 or $20 \mu \mathrm{l}$ suspension liquid was implemented, while very few employed volumes as high as $50 \mu \mathrm{l}$ (Hua et al. 2010; Lu et al. 2011) and even up to $100 \mu \mathrm{l}$ (Zhang et al. 2016). High volumes seemed to have been used especially to counteract evaporation processed as they were used mostly together with long treatment times above $1 \mathrm{~min}$ and at high gas flow rates. In contrast, some cases reported the pre-drying of the sample on the sample plate prior to plasma treatment (Liu et al. 2013; Li et al. 2014; Wang et al. 2014a, b).

\section{Post-treatment variables}

After the ARTP treatment, the sample plates are submerged in resuspension liquid. A resuspension volume of $1 \mathrm{ml}$ and a vortexing time of at least $1 \mathrm{~min}$ are recommended to ensure complete resuspension. The resuspension liquid acts as a radical scavenger equally to the suspension liquid during the ARTP treatment. Furthermore, the ratio between the treated volume and the resuspending media was found to be of importance. Cell samples treated with a dielectric barrier discharge plasma were affected more at lower than at higher dilutions indicating that the concentration of reactive chemical species and the length of the exposure are relevant (Kalghatgi 
et al. 2011). However, there are no reports on the influence of the vortexing time or intensity on the survival of plasma-treated cells. The subsequent dilution range before spreading the sample on agar is dependent on the plasma treatment severity and the initial cell concentration. In general, a consistent post-treatment procedure and especially homogeneous cell dilutions needs to be ensured to obtain isolated colonies in high reliability. Data describing the post-treatment are limited. Overall, the used resuspension liquids were the same as the suspension liquid used for the plasma treatment. The volume was set between 0.8 and $2 \mathrm{ml}$, while in one case, even $5 \mathrm{ml}$ was used ( $\mathrm{Li}$ et al. 2014). This determines the ratio, as discussed earlier, which is possibly important to stop further exposure of the sample to reactive chemical species. More information about post-treatment details such as vortex intensity, dilution range, or spread volume were rarely given.

\section{Combined usage of the ARTP system with other methods} Most studies reported a single ARTP treatment to yield the desired target. However, some studies reported an iterative ARTP treatment. While an iterative treatment for eight times (Jiang et al. 2017) led to a steady increase of the desired phenotype, 30 repetitions were only used to produce a larger pool of possible mutants (Luo et al. 2017b). ARTP treatment was also combined together with other treatments such as chemical mutagenesis with diethyl sulfate (Li et al. 2015), nitrosoguanidine (Zhang et al. 2016) or radiation mutagenesis with UV and UV$\mathrm{NaNO}_{2}$ (Wang et al. 2017). However, due to the lack of comparative studies, it cannot be concluded if an iterative ARTP treatment or a combination of ARTP with traditional mutagenesis tools is superior over a single ARTP treatment. Apart from applying ARTP in straightforward mutagenesis approaches, ARTP was also successfully used as a tool for the construction of libraries for genome shuffling (Xu et al. 2012; Zhang et al. 2015b; Gu et al. 2017).

\section{Biotechnological applications}

The core component of ARTP, the RF APGD plasma jet generator, was first used with helium as working gas in a proof of concept study for the generation of Streptomyces avermitilis mutants in 2010 (Wang et al. 2010). Since then, a multitude of case studies were published in Chinese and international journals with the majority of more than $80 \%$ published after 2014 (Fig. 2).

\section{Microorganisms}

Between 2010 and 2018, a total of 42 different microbial species in 73 case studies can be found in international literature (Table 1) which include Gram-negative bacteria
(9 species/17 studies), Gram-positive bacteria (15 species/26 studies), filamentous fungi (6 species/8 studies), yeast ( 8 species/15 studies), species not belonging to the classes mentioned above ( 3 species $/ 6$ studies) and even a whole microbial community. Together with studies published in Chinese language, more than 300 ARTP case studies are estimated to be currently available. Almost all species are classified as Biosafety Level 1 strains, and most are used in biotechnological research and industry like E. coli and B. subtilis.

\section{Mutagenesis targets}

Overall, mutagenesis targets can be classified into six groups, namely, (i) increase of microbial tolerance to certain growth conditions and media compounds, (ii) growth increase and optimization of biomass-related parameters, (iii) enzyme activity increase, (iv) butanol production increase, (v) production increase of organic acids and their derivates, and (vi) production increase of specialty chemicals mainly used in pharmaceutical products. As there are numerous positive achievements reported, only selected outstanding examples can be outlined in detail. In a study comprising three publications involving the yeast Rhodosporidium toruloides, three mutants were isolated which were resistant to the growth inhibitors vanillin, furfural, and acetic acid and, therefore, could grow in sugar cane bagasse hydrolysate (Kitahara et al. 2014). Subsequently, the mutant with the highest tolerance towards inhibitors was identified (Qi et al. 2014) and further investigated using a mixed transcriptome/ proteome approach. Thirty-nine genes were identified with a larger than fivefold increased transcription level belonging to the cluster of nucleotide excision repair, glycolysis, spliceosome assembly, and MAPK signalling (Qi et al. 2017). In another study, a B. subtilis mutant showed a $37.9 \%$ increase in extracellular protein concentration which resulted in an overall higher recombinant protein

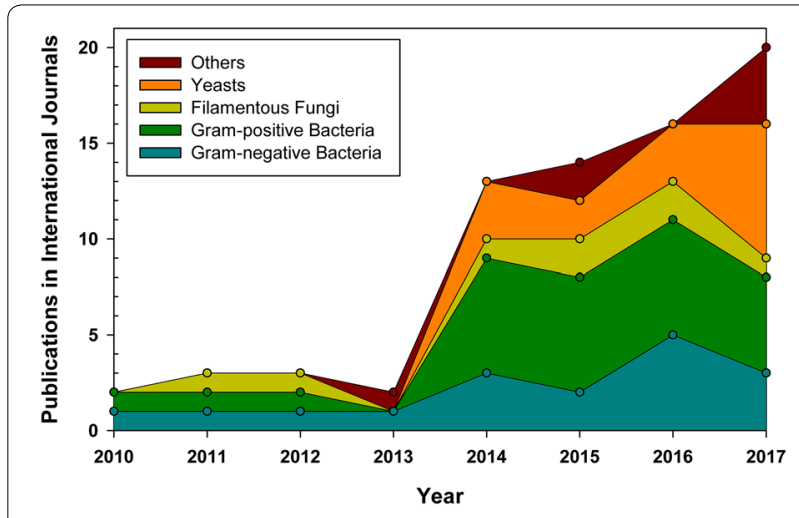

Fig. 2 International publications from 2009 to 2018 involving the ARTP split into Gram-positive/Gram-negative bacteria, fungi and other organisms 


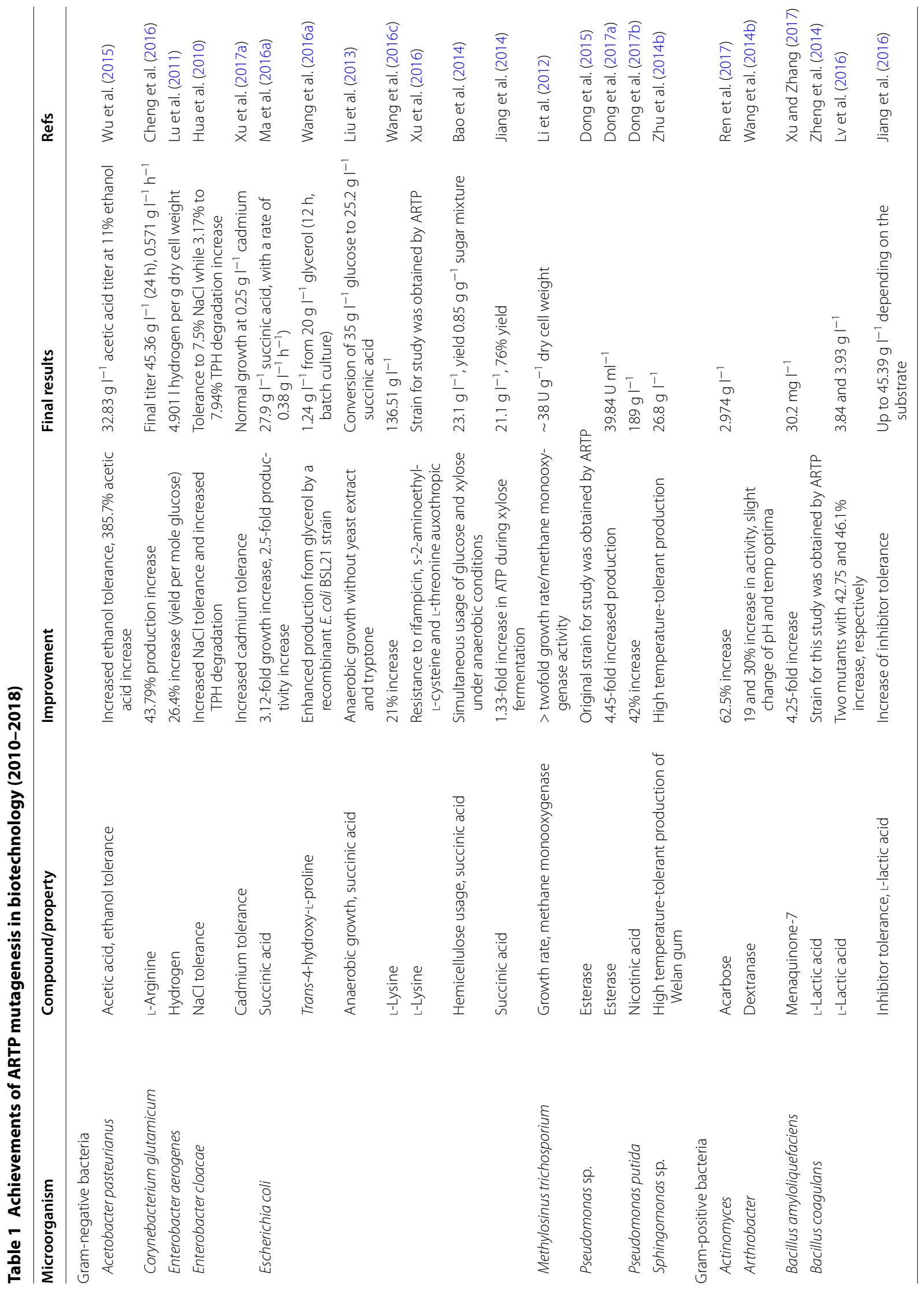




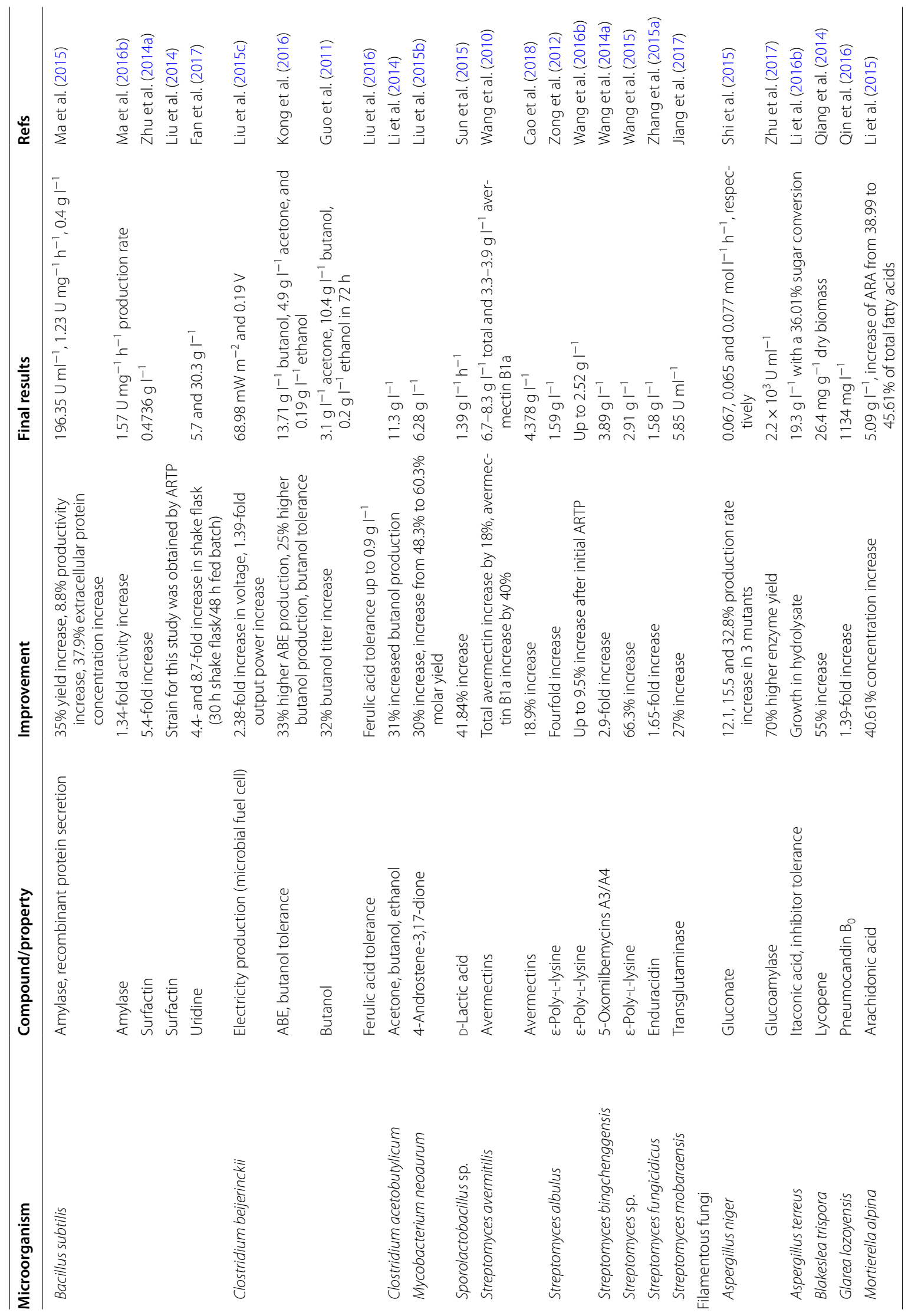




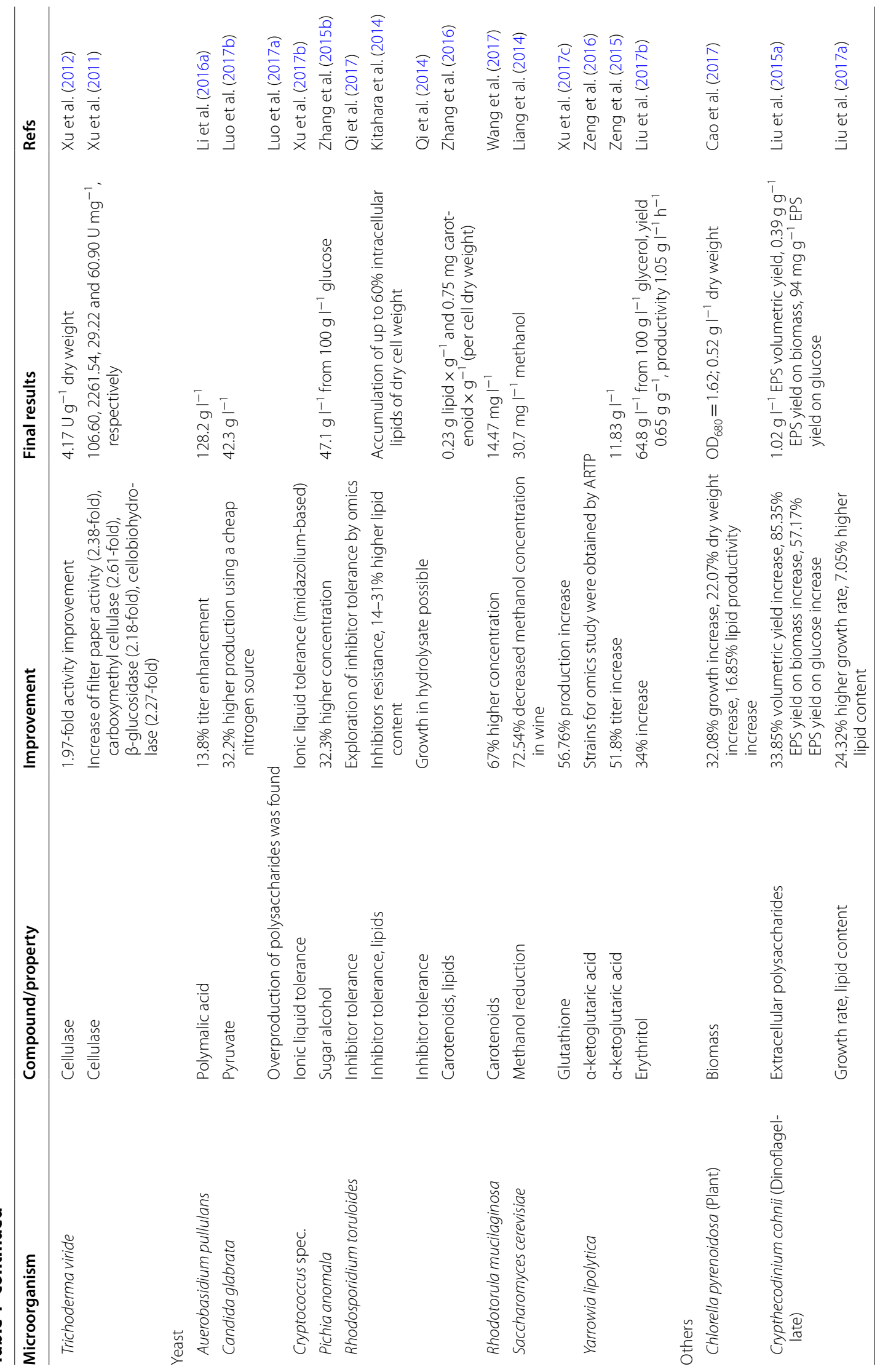




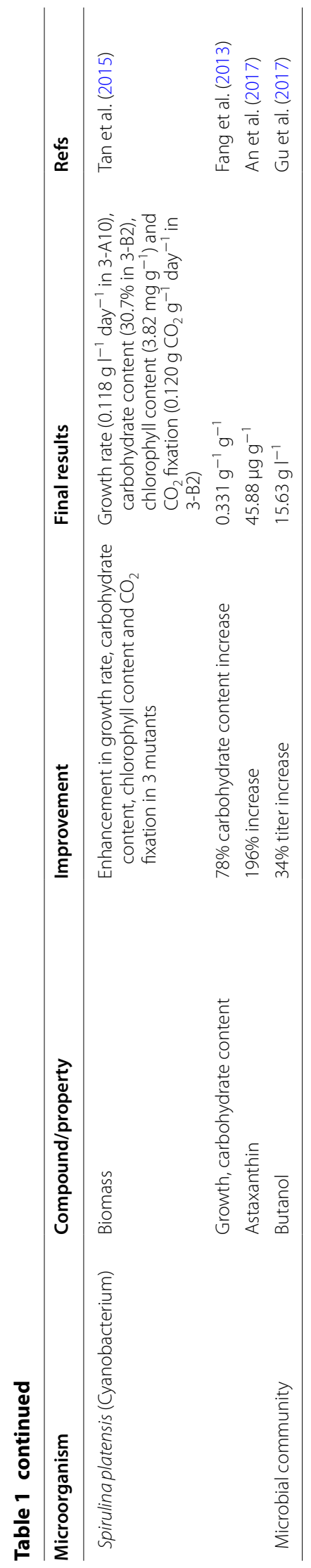


secretion (Ma et al. 2015). The increase in butanol production by ARTP was shown several times such as in a mutant which exhibited a 33\% higher ABE solvents production and a $25 \%$ higher butanol production $\left(12.53 \mathrm{~g} \mathrm{l}^{-1}\right.$ total ABE solvents, $4.9 \mathrm{~g} \mathrm{l}^{-1}$ acetone, $13.71 \mathrm{~g} \mathrm{l}^{-1}$ butanol, and $0.19 \mathrm{~g} \mathrm{l}^{-1}$ ethanol) when compared to its wild type (Kong et al. 2016). The enzymes of the cellulase complex in Trichoderma viridae were investigated individually after ARTP treatment. A 2.38-fold increase of filter paper activity, 2.61-fold increase of carboxymethyl cellulase activity, 2.18-fold increase in $\beta$-glucosidase activity (EC 3.1.2.21), and a 2.27-fold increase in cellobiohydrolase (EC 3.2.1.91) activity was reported (Xu et al. 2011). The organic acid 1-lactic acid produced by an ARTP mutant of Bacillus coagulans reached a titer of $90.2 \mathrm{~g} \mathrm{l}^{-1}$ from $100 \mathrm{~g} \mathrm{l}^{-1}$ xylose, while $23.49 \mathrm{~g} \mathrm{l}^{-1}$ from corn stover with a yield of 83.09\% was achieved (Zheng et al. 2014). The carotenoid lycopene, a specialty chemical used as a pigment and antioxidant, showed a $55 \%$ concentration increase to $19.3 \mathrm{~g} \mathrm{l}^{-1}$ in Blakeslea trispora mutants (Qiang et al. 2014).

\section{Concluding remarks}

ARTP has been proven to be a reliable and effective microbial breeding system leading to high frequency of random mutations induced by reactive chemical species which are produced by the helium-based atmospheric and roomtemperature plasma. Its application has been reported to be successful in various studies involving diverse bacterial and fungal species for improving strain properties such as tolerance to medium components and growth conditions and increasing production of valuable products like cellular biomass, enzymes, bulk, and specialty chemicals. However, there are still theoretical and technical questions open for clarification, whose absence might delay the widespread use of the ARTP mutagenesis system including:

1. The factors involved in the operation of the system, their interactions, and the severity of their impact on the resulting mutagenic effects. Developing an automatic and quantifiable parameter setup for effective plasma treatment would be an essential prerequisite for wider applications of the ARTP mutagenesis breeding system.

2. The systematic clarification of the susceptibility of different microorganisms and their growth stages to the ARTP treatment are required for the development of Standard Operation Protocols. Unfortunately, many case studies did not indicate precisely the status of all operational parameters making it difficult for a susceptibility estimation of different microorganisms to the sub-lethal plasma treatment.

3. More omics studies are needed to gain a deeper scientific insight of the mutagenic impact of ARTP to widen the applications of ARTP-induced gene mutations not only in cellular breeding but also in other fields such as directed evolution of enzymes. The combined use of ARTP with other mutation methods such as $\gamma$-ray or with rational mutations such as CRISPR/Cas9 might give additional advantages in improving microbes, which is worth investigating.

\section{Abbreviations}

ARA: arachidonic acid; ARTP: atmospheric and room-temperature plasma; ABE: acetone-butanol-ethanol; CRISPR/Cas9: clustered regularly interspaced short palindromic repeats/Cas9; DNA: deoxyribonucleic acid; EDTA: ethylenediaminetetraacetic acid; EPS: extracellular polysaccharides; GMO: genetically modified organism; MAPK pathway: mitogen-activated protein kinase pathway; OD: optical density; PBS: phosphate-buffered saline; RF APGD plasma: radiofrequency atmospheric-pressure glow discharge plasma; SLPM: standard liters per minute; TPH: total petroleum hydrocarbon; UV: ultraviolet.

\section{Authors' contributions}

CO collected the data and prepared the draft manuscript. MN and JCW revised the manuscript. All authors read and approved the final manuscript.

\section{Author details}

${ }^{1}$ Institute of Chemical and Engineering Sciences, Agency for Sciences, Technology and Research (A*STAR), 1 Pesek Road, Singapore 627833, Singapore.

${ }^{2}$ Microbiology and Bioprocess Engineering, Institute of Biochemistry, Leipzig University, 604103 Leipzig, Germany.

\section{Acknowledgements}

This work was supported by the Science and Engineering Research Council (SERC) of the Agency for Science, Technology and Research (A*STAR), Singapore, under the Biomass to Speciality Chemicals Program (SERC Grant No. 1526004159, ICES/15-175A02) and through the A*STAR Research Attachment Program (ARAP) Scholarship.

\section{Competing interests}

The authors declare that they have no competing interests.

\section{Ethics approval and consent to participate}

Not applicable.

Funding

There is no funding source.

\section{Publisher's Note}

Springer Nature remains neutral with regard to jurisdictional claims in published maps and institutional affiliations.

Received: 19 February 2018 Accepted: 18 March 2018

Published online: 23 March 2018

\section{References}

An J, Gao F, Ma Q, Xiang Y, Ren D, Lu J (2017) Screening for enhanced astaxanthin accumulation among Spirulina platensis mutants generated by atmospheric and room temperature plasmas. Algal Res 25:464-472. https://doi.org/10.1016/j.algal.2017.06.006

Arjunan K, Sharma V, Ptasinska S (2015) Effects of atmospheric pressure plasmas on isolated and cellular DNA—a review. Int J Mol Sci 16:2971-3016. https://doi.org/10.3390/ijms16022971

Bao H, Liu R, Liang L, Jiang Y, Jiang M, Ma J, Chen K, Jia H, Wei P, Ouyang P (2014) Succinic acid production from hemicellulose hydrolysate by an Escherichia coli mutant obtained by atmospheric and room temperature plasma and adaptive evolution. Enzyme Microb Technol 66:10-15. https://doi.org/10.1016/j.enzmictec.2014.04.017 
Barrangou R, Horvath P (2017) A decade of discovery: CRISPR functions and applications. Nat Microbiol 2:17092. https://doi.org/10.1038/ nmicrobiol.2017.92

Bogaerts A, Neyts E, Gijbels R, van der Mullen J (2002) Gas discharge plasmas and their applications. Spectrochim Acta Part B At Spectrosc 57:609-658. https://doi.org/10.1016/S0584-8547(01)00406-2

Bridges BA (2001) SOS repair. In: Brenner S and Miller JH (eds) Encyclopedia of genetics. Elsevier Science, pp 1853-1855

Cao S, Zhou X, Jin W, Wang F, Tu R, Han S, Chen H, Chen C, Xie GJ, Ma F (2017) Improving of lipid productivity of the oleaginous microalgae Chlorella pyrenoidosa via atmospheric and room temperature plasma (ARTP). Bioresour Technol 244:1400-1406. https://doi.org/10.1016/j. biortech.2017.05.039

Cao X, Luo Z, Zeng W, Xu S, Zhao L, Zhou J (2018) Enhanced avermectin production by Streptomyces avermitilis ATCC 31267 using high-throughput screening aided by fluorescence-activated cell sorting. Appl Microbiol Biotechnol 102:703-712. https://doi.org/10.1007/s00253-017-8658-X

Cheng G, Xu J, Xia X, Guo Y, Xu K, Su C, Zhang W (2016) Breeding L-arginineproducing strains by a novel mutagenesis method: atmospheric and room temperature plasma (ARTP). Prep Biochem Biotechnol 46:509-516. https://doi.org/10.1080/10826068.2015.1084634

Dong J, Zhao W, Gasmalla MAA, Sun J, Hua X, Zhang W, Han L, Fan Y, Feng Y, Shen Q, Yang R (2015) A novel extracellular cold-active esterase of Pseudomonas sp. TB11 from glacier No. 1: differential induction, purification and characterisation. J Mol Catal B Enzym 121:53-63. https://doi. org/10.1016/j.molcatb.2015.07.015

Dong J, Gasmalla MAA, Zhao W, Sun J, Liu W, Wang M, Han L, Yang R (2017a) Characterization of a cold-adapted esterase and mutants from a psychotolerant Pseudomonas sp. strain. Biotechnol Appl Biochem 64:686-699. https://doi.org/10.1002/bab.1525

Dong T-T, Gong J-S, Gu B-C, Zhang Q, Li H, Lu Z-M, Lu M-L, Shi J-S, Xu Z-H (2017b) Significantly enhanced substrate tolerance of Pseudomonas putida nitrilase via atmospheric and room temperature plasma and cell immobilization. Bioresour Technol 244:1104-1110. https://doi. org/10.1016/j.biortech.2017.08.039

Ermolaeva SA, Varfolomeev AF, Chernukha MY, Yurov DS, Vasiliev MM, Kaminskaya AA, Moisenovich MM, Romanova JM, Murashev AN, Selezneva II, Shimizu T, Sysolyatina EV, Shaginyan IA, Petrov OF, Mayevsky El, Fortov VE, Morfill GE, Naroditsky BS, Gintsburg AL (2011) Bactericidal effects of non-thermal argon plasma in vitro, in biofilms and in the animal model of infected wounds. J Med Microbiol 60:75-83. https://doi.org/10.1099/ jmm.0.020263-0

Fan X, Wu H, Li G, Yuan H, Zhang H, Li Y, Xie X, Chen N (2017) Improvement of uridine production of Bacillus subtilis by atmospheric and room temperature plasma mutagenesis and high-throughput screening. PLOS ONE 12:e0176545. https://doi.org/10.1371/journal.pone.0176545

Fang M, Jin L, Zhang C, Tan Y, Jiang P, Ge N, Li Heping, Xing X (2013) Rapid mutation of Spirulina platensis by a new mutagenesis system of atmospheric and room temperature plasmas (ARTP) and generation of a mutant library with diverse phenotypes. PLOS ONE 8:e77046. https://doi. org/10.1371/journal.pone.0077046

Gu C, Wang G, Mai S, Wu P, Wu J, Wang G, Liu H, Zhang J (2017) ARTP mutation and genome shuffling of $A B E$ fermentation symbiotic system for improvement of butanol production. Appl Microbiol Biotechnol 101:2189-2199. https://doi.org/10.1007/s00253-017-8093-z

Guo T, Tang Y, Xi YL, He AY, Sun BJ, Wu H, Liang DF, Jiang M, Ouyang PK (2011) Clostridium beijerinckii mutant obtained by atmospheric pressure glow discharge producing high proportions of butanol and solvent yields. Biotechnol Lett 33:2379-2383. https://doi.org/10.1007/s10529-011-0702-9

Hua X, Wang J, Wu Z, Zhang H, Li H, Xing X, Liu Z (2010) A salt tolerant Enterobacter cloacae mutant for bioaugmentation of petroleum- and saltcontaminated soil. Biochem Eng J 49:201-206. https://doi.org/10.1016/j. bej.2009.12.014

Jiang M, Wan Q, Liu R, Liang L, Chen X, Wu M, Zhang H, Chen K, Ma J, Wei P, Ouyang P (2014) Succinic acid production from corn stalk hydrolysate in an E. coli mutant generated by atmospheric and room-temperature plasmas and metabolic evolution strategies. J Ind Microbiol Biotechnol 41:115-123. https://doi.org/10.1007/s10295-013-1346-7

Jiang T, Qiao H, Zheng Z, Chu Q, Li X, Yong Q, Ouyang J (2016) Lactic acid production from pretreated hydrolysates of corn stover by a newly developed Bacillus coagulans strain. PLoS ONE 11:e0149101. https://doi org/10.1371/journal.pone.0149101

Jiang Y, Shang Y-P, Li H, Zhang C, Pan J, Bai Y-P, Li C-X, Xu J-H (2017) Enhancing transglutaminase production of Streptomyces mobaraensis by iterative mutagenesis breeding with atmospheric and room-temperature plasma (ARTP). Bioresour Bioprocess 4:37. https://doi.org/10.1186/ s40643-017-0168-2

Kalghatgi S, Kelly CM, Cerchar E, Torabi B, Alekseev O, Fridman A, Friedman G, Azizkhan-Clifford J (2011) Effects of non-thermal plasma on mammalian cells. PLOS ONE 6:e16270. https://doi.org/10.1371/journal.pone.0016270

Kim OC, Kim SY, Hwang DH, Oh DB, Kang HA, Kwon O (2013) Development of a genome-wide random mutagenesis system using proofreadingdeficient DNA polymerase $\delta$ in the methylotrophic yeast Hansenula polymorpha. J Microbiol Biotechnol 23:304-312. https://doi.org/10.4014/ jmb.1211.11048

Kitahara Y, Yin T, Zhao X, Wachi M, Du W, Liu D (2014) Isolation of oleaginous yeast (Rhodosporidium toruloides) mutants tolerant of sugarcane bagasse hydrolysate. Biosci Biotechnol Biochem 78:336-342. https://doi.org/10.10 80/09168451.2014.882746

Kong X, He A, Zhao J, Wu H, Ma J, Wei C, Jin W, Jiang M (2016) Efficient acetone-butanol-ethanol (ABE) production by a butanol-tolerant mutant of Clostridium beijerinckii in a fermentation-pervaporation coupled process. Biochem Eng J 105:90-96. https://doi.org/10.1016/j.bej.2015.09.013

Kramer A, Bekeschus S, Matthes R, Bender C, Stope MB, Napp M, Lademann O, Lademann J, Weltmann KD, Schauer F (2015) Cold physical plasmas in the field of hygiene-relevance, significance, and future applications. Plasma Process Polym 12:1410-1422. https://doi.org/10.1002/ppap.201500170

Lackmann JW, Bandow JE (2014) Inactivation of microbes and macromolecules by atmospheric-pressure plasma jets. Appl Microbiol Biotechnol 98:6205-6213. https://doi.org/10.1007/s00253-014-5781-9

Lackmann J-W, Schneider S, Edengeiser E, Jarzina F, Brinckmann S, Steinborn E, Havenith M, Benedikt J, Bandow JE (2013) Photons and particles emitted from cold atmospheric-pressure plasma inactivate bacteria and biomolecules independently and synergistically. J R Soc Interface 10:20130591. https://doi.org/10.1098/rsif.2013.0591

Leduc M, Guay D, Leask RL, Coulombe S (2009) Cell permeabilization using a non-thermal plasma. New J Phys 11:115021. https://doi. org/10.1088/1367-2630/11/11/115021

Lee K, Paek K-H, Ju W-T, Lee Y (2006) Sterilization of bacteria, yeast, and bacterial endospores by atmospheric-pressure cold plasma using helium and oxygen. J Microbiol Microbiol Soc Korea 44:269-275

Li G, Li H-P, Wang L-Y, Wang S, Zhao H-X, Sun W-T, Xing X-H, Bao C-Y (2008) Genetic effects of radio-frequency, atmospheric-pressure glow discharges with helium. Appl Phys Lett 92:221504. https://doi. org/10.1063/1.2938692

Li HP, Wang ZB, Ge N, Le PS, Wu H, Lu Y, Wang LY, Zhang C, Bao CY, Xing XH (2012) Studies on the physical characteristics of the radio-frequency atmospheric-pressure glow discharge plasmas for the genome mutation of Methylosinus trichosporium. IEEE Trans Plasma Sci 40:2853-2860. https://doi.org/10.1109/TPS.2012.2213274

Li H, Luo W, Wang Q, Yu X (2014) Direct fermentation of gelatinized cassava starch to acetone, butanol, and ethanol using Clostridium acetobutylicum mutant obtained by atmospheric and room temperature plasma. Appl Biochem Biotechnol 172:3330-3341. https://doi.org/10.1007/ s12010-014-0765-X

Li X, Liu R, Li J, Chang M, Liu Y, Jin Q, Wang X (2015) Enhanced arachidonic acid production from Mortierella alpina combining atmospheric and room temperature plasma (ARTP) and diethyl sulfate treatments. Bioresour Technol 177:134-140. https://doi.org/10.1016/j.biortech.2014.11.051

Li H, Li T, Zuo H, Xiao S, Guo M, Jiang M, Li Z, Li Y, Zou X (2016a) A novel rhodamine-based fluorescent $\mathrm{pH}$ probe for high-throughput screening of high-yield polymalic acid strains from random mutant libraries. RSC Adv 6:94756-94762. https://doi.org/10.1039/c6ra20394a

Li X, Zheng K, Lai C, Ouyang J, Yong Q (2016b) Improved itaconic acid production from undetoxified enzymatic hydrolysate of steam-exploded corn stover using an Aspergillus terreus mutant generated by atmospheric and room temperature plasma. BioResources 11:9047-9058. https://doi. org/10.15376/biores.11.4.9047-9058

Liang MH, Liang YJ, Chai JY, Zhou SS, Jiang JG (2014) Reduction of methanol in brewed wine by the use of atmospheric and roomtemperature plasma method and the combination optimization of 
malt with different adjuncts. J Food Sci 79:M2308-M2314. https://doi. org/10.1111/1750-3841.12660

Liu R, Liang L, Ma J, Ren X, Jiang M, Chen K, Wei P, Ouyang P (2013) An engineering Escherichia coli mutant with high succinic acid production in the defined medium obtained by the atmospheric and room temperature plasma. Process Biochem 48:1603-1609. https://doi.org/10.1016/j. procbio.2013.07.020

Liu Q, Lin J, Wang W, Huang H, Li S (2014) Production of surfactin isoforms by Bacillus subtilis BS-37 and its applicability to enhanced oil recovery under laboratory conditions. Biochem Eng J 93:31-37. https://doi.org/10.1016/j. bej.2014.08.023

Liu B, Sun Z, Ma X, Yang B, Jiang Y, Wei D, Chen F (2015a) Mutation breeding of extracellular polysaccharide-producing microalga Crypthecodinium cohnii by a novel mutagenesis with atmospheric and room temperature plasma. Int J Mol Sci 16:8201-8212. https://doi.org/10.3390/ ijms16048201

Liu C, Zhang X, Rao Z, Shao M, Zhang L, Wu D, Xu Z, Li H (2015b) Mutation breeding of high 4-androstene-3,17-dione-producing Mycobacterium neoaurum ZADF-4 by atmospheric and room temperature plasma treatment. J Zhejiang Univ Sci B 16:286-295. https://doi.org/10.1631/jzus. B1400274

Liu J, Guo T, Wang D, Ying H (2015c) Clostridium beijerinckii mutant obtained atmospheric pressure glow discharge generates enhanced electricity in a microbial fuel cell. Biotechnol Lett 37:95-100. https://doi.org/10.1007/ s10529-014-1649-4

Liu J, Guo T, Wang D, Xu J, Ying H (2016) Butanol production by a Clostridium beijerinckii mutant with high ferulic acid tolerance. Biotechnol Appl Biochem 63:727-733. https://doi.org/10.1002/bab.1418

Liu J, Pei G, Diao J, Chen Z, Liu L, Chen L, Zhang W (2017a) Screening and transcriptomic analysis of Crypthecodinium cohnii mutants with high growth and lipid content using the acetyl-CoA carboxylase inhibitor sethoxydim. Appl Microbiol Biotechnol 101:6179-6191. https://doi.org/10.1007/ s00253-017-8397-z

Liu X, Lv J, Xu J, Xia J, Dai B, Xu X, Xu J (2017b) Erythritol production by Yarrowia lipolytica mutant strain M53 generated through atmospheric and room temperature plasma mutagenesis. Food Sci Biotechnol 26:979-986. https://doi.org/10.1007/s10068-017-0116-0

Lu Y, Wang L, Ma K, Li G, Zhang C, Zhao H, Lai Q, Li HP, Xing XH (2011) Characteristics of hydrogen production of an Enterobacter aerogenes mutant generated by a new atmospheric and room temperature plasma (ARTP). Biochem Eng J 55:17-22. https://doi.org/10.1016/j.bej.2011.02.020

Lu H, Patil S, Keener KM, Cullen PJ, Bourke P (2014) Bacterial inactivation by high-voltage atmospheric cold plasma: influence of process parameters and effects on cell leakage and DNA. J Appl Microbiol 116:784-794. https://doi.org/10.1111/jam.12426

Luo Z, Liu S, Du G, Zhou J, Chen J (2017a) Identification of a polysaccharide produced by the pyruvate overproducer Candida glabrata CCTCC M202019. Appl Microbiol Biotechnol 101:4447-4458. https://doi, org/10.1007/s00253-017-8245-1

Luo Z, Zeng W, Du G, Liu S, Fang F, Zhou J, Chen J (2017b) A high-throughput screening procedure for enhancing pyruvate production in Candida glabrata by random mutagenesis. Bioprocess Biosyst Eng 40:693-701. https://doi.org/10.1007/s00449-017-1734-x

Lv X, Song J, Yu B, Liu H, Li C, Zhuang Y, Wang Y (2016) High-throughput system for screening of high I-lactic acid-productivity strains in deep-well microtiter plates. Bioprocess Biosyst Eng 39:1737-1747. https://doi. org/10.1007/s00449-016-1649-y

Ma Y, Yang H, Chen X, Sun B, Du G, Zhou Z, Song J, Fan Y, Shen W (2015) Significantly improving the yield of recombinant proteins in Bacillus subtilis by a novel powerful mutagenesis tool (ARTP): alkaline a-amylase as a case study. Protein Expr Purif 114:82-88. https://doi.org/10.1016/j. pep.2015.06.016

Ma J, Wu M, Zhang C, He A, Kong X, Li G, Wei C, Jiang M (2016a) Coupled ARTP and ALE strategy to improve anaerobic cell growth and succinic acid production by Escherichia coli. J Chem Technol Biotechnol 91:711-717. https://doi.org/10.1002/jctb.4633

Ma Y, Shen W, Chen X, Liu L, Zhou Z, Xu F, Yang H (2016b) Significantly enhancing recombinant alkaline amylase production in Bacillus subtilis by integration of a novel mutagenesis-screening strategy with systems-level fermentation optimization. J Biol Eng 10:13. https://doi.org/10.1186/ s13036-016-0035-2
Misra NN, Pankaj SK, Segat A, Ishikawa K (2016) Cold plasma interactions with enzymes in foods and model systems. Trends Food Sci Technol 55:39-47. https://doi.org/10.1016/j.tifs.2016.07.001

O'Connell D, Cox LJ, Hyland WB, McMahon SJ, Reuter S, Graham WG, Gans T, Currell FJ (2011) Cold atmospheric pressure plasma jet interactions with plasmid DNA. Appl Phys Lett 98:43701. https://doi.org/10.1063/1.3521502

Pompl R, Jamitzky F, Shimizu T, Steffes B, Bunk W, Schmidt H-U, Georgi M, Ramrath K, Stolz W, Stark RW, Urayama T, Fujii S, Morfill GE (2009) The effect of low-temperature plasma on bacteria as observed by repeated AFM imaging. New J Phys 11:115023. https://doi. org/10.1088/1367-2630/11/11/115023

Qi F, Kitahara Y, Wang Z, Zhao X, Du W, Liu D (2014) Novel mutant strains of Rhodosporidium toruloides by plasma mutagenesis approach and their tolerance for inhibitors in lignocellulosic hydrolyzate. J Chem Technol Biotechnol 89:735-742. https://doi.org/10.1002/jctb.4180

Qi F, Zhao X, Kitahara Y, Li T, Ou X, Du W, Liu D, Huang J (2017) Integrative transcriptomic and proteomic analysis of the mutant lignocellulosic hydrolyzate-tolerant Rhodosporidium toruloides. Eng Life Sci 17:249-261. https://doi.org/10.1002/elsc.201500143

Qiang W, Ling-ran F, Luo W, Han-guang L, Lin W, Ya Z, Xiao-bin Y (2014) Mutation breeding of lycopene-producing strain Blakeslea trispora by a novel atmospheric and room temperature plasma (ARTP). Appl Biochem Biotechnol 174:452-460. https://doi.org/10.1007/s12010-014-0998-8

Qin T, Song P, Wang X, Ji X, Ren L, Huang H (2016) Protoplast mutant selection of Glarea lozoyensis and statistical optimization of medium for pneumocandin B0 yield-up. Biosci Biotechnol Biochem 80:2241-2246. https:// doi.org/10.1080/09168451.2016.1196575

Ren F, Chen L, Tong Q (2017) Highly improved acarbose production of Actinomyces through the combination of ARTP and penicillin susceptible mutant screening. World J Microbiol Biotechnol 33:16. https://doi. org/10.1007/s11274-016-2156-7

Shi F, Tan J, Chu J, Wang Y, Zhuang Y, Zhang S (2015) A qualitative and quantitative high-throughput assay for screening of gluconate high-yield strains by Aspergillus niger. J Microbiol Methods 109:134-139. https://doi. org/10.1016/j.mimet.2014.12.004

Sun J, Wang Y, Wu B, Bai Z, He B (2015) Enhanced production of d -lactic acid by Sporolactobacillus sp. Y2-8 mutant generated by atmospheric and room temperature plasma. Biotechnol Appl Biochem 62:287-292. https:// doi.org/10.1002/bab.1267

Tan Y, Fang M, Jin L, Zhang C, Li H-P, Xing X-H (2015) Culture characteristics of the atmospheric and room temperature plasma-mutated Spirulina platensis mutants in $\mathrm{CO}_{2}$ aeration culture system for biomass production. J Biosci Bioeng 120:438-443. https://doi.org/10.1016/j.jbiosc.2015.02.012

Tendero C, Tixier C, Tristant P, Desmaison J, Leprince P (2006) Atmospheric pressure plasmas: a review. Spectrochim Acta Part B At Spectrosc 61:2-30. https://doi.org/10.1016/j.sab.2005.10.003

Twardowski T, Małyska A (2015) Uninformed and disinformed society and the GMO market. Trends Biotechnol 33:1-3. https://doi.org/10.1016/j. tibtech.2014.11.006

Wang L-Y, Huang Z-L, Li G, Zhao H-X, Xing X-H, Sun W-T, Li H-P, Gou Z-X, Bao C-Y (2010) Novel mutation breeding method for Streptomyces avermitilis using an atmospheric pressure glow discharge plasma. J Appl Microbiol 108:851-858. https://doi.org/10.1111/j.1365-2672.2009.04483.x

Wang ZB, Le PS, Ge N, Nie QY, Li HP, Bao CY (2012) One-dimensional modeling on the asymmetric features of a radio-frequency atmospheric helium glow discharge produced using a Co-Axial-type plasma generator. Plasma Chem Plasma Process 32:859-874. https://doi.org/10.1007/ s11090-012-9367-y

Wang $\mathrm{H}-\mathrm{Y}$, Zhang J, Zhang Y-J, Zhang B, Liu C-X, He H-R, Wang X-J, Xiang W-S (2014a) Combined application of plasma mutagenesis and gene engineering leads to 5-oxomilbemycins A3/A4 as main components from Streptomyces bingchenggensis. Appl Microbiol Biotechnol 98:9703-9712. https://doi.org/10.1007/s00253-014-5970-6

Wang X, Lu M, Wang S, Fang Y, Wang D, Ren W, Zhao G (2014b) The atmospheric and room-temperature plasma (ARTP) method on the dextranase activity and structure. Int J Biol Macromol 70:284-291. https://doi. org/10.1016/j.jijbiomac.2014.07.006

Wang L, Chen X, Wu G, Li S, Zeng X, Ren X, Tang L, Mao Z (2015) Improved $\varepsilon$-poly-L-lysine production of Streptomyces sp. FEEL-1 by atmospheric and room temperature plasma mutagenesis and streptomycin resistance 
screening. Ann Microbiol 65:2009-2017. https://doi.org/10.1007/ s13213-015-1039-8

Wang J, Zhang Z, Liu H, Sun FF, Yue C, Hu J, Wang C (2016a) Construction and optimization of trans-4-hydroxy-L-proline production recombinant $E$. coli strain taking the glycerol as carbon source. J Chem Technol Biotechnol 91:2389-2398. https://doi.org/10.1002/jctb.5024

Wang L, Chen X, Wu G, Zeng X, Ren X, Li S, Tang L, Mao Z (2016b) Genome shuffling and gentamicin-resistance to improve $\varepsilon$-poly-L-lysine productivity of Streptomyces albulus W-156. Appl Biochem Biotechnol 180:16011617. https://doi.org/10.1007/s12010-016-2190-9

Wang Y, Li Q, Zheng P, Guo Y, Wang L, Zhang T, Sun J, Ma T (2016c) Evolving the L-lysine high-producing strain of Escherichia coli using a newly developed high-throughput screening method. J Ind Microbiol Biotechnol 43:1227-1235. https://doi.org/10.1007/s10295-016-1803-1

Wang Q, Liu D, Yang Q, Wang P (2017) Enhancing carotenoid production in Rhodotorula mucilaginosa KC8 by combining mutation and metabolic engineering. Ann Microbiol 67:425-431. https://doi.org/10.1007/ s13213-017-1274-2

Winter T, Bernhardt J, Winter J, Mäder U, Schlüter R, Weltmann KD, Hecker M, Kusch H (2013) Common versus noble Bacillus subtilis differentially responds to air and argon gas plasma. Proteomics 13:2608-2621. https:// doi.org/10.1002/pmic.201200343

Wu X, Wei Y, Xu Z, Liu L, Tan Z, Jia S (2015) Evaluation of an ethanol-tolerant Acetobacter pasteurianus mutant generated by a new atmospheric and room temperature plasma (ARTP). Lect Notes Electr Eng 333:277-286. https://doi.org/10.1007/978-3-662-46318-5_30

Xu J, Zhang W (2017) Menaquinone-7 production from maize meal hydrolysate by Bacillus isolates with diphenylamine and analogue resistance. J Zhejiang Univ Sci B 18:462-473. https://doi.org/10.1631/jzus.B1600127

Xu F, Wang J, Chen S, Qin W, Yu Z, Zhao H, Xing X, Li H (2011) Strain improvement for enhanced production of cellulase in Trichoderma viride. Appl Biochem Microbiol 47:53-58. https://doi.org/10.1134/ S0003683811010212

Xu F, Jin H, Li H, Tao L, Wang J, Lv J, Chen S (2012) Genome shuffling of Trichoderma viride for enhanced cellulase production. Ann Microbiol 62:509-515. https://doi.org/10.1007/s13213-011-0284-8

Xu J, Han M, Ren X, Zhang W (2016) Modification of aspartokinase III and dihydrodipicolinate synthetase increases the production of L-lysine in Escherichia coli. Biochem Eng J 114:79-86. https://doi.org/10.1016/j. bej.2016.06.025

Xu C, He S, Liu Y, Zhang W, Lu D (2017a) Bioadsorption and biostabilization of cadmium by Enterobacter cloacae TU. Chemosphere 173:622-629. https:// doi.org/10.1016/j.chemosphere.2017.01.005

Xu J, Zhou S, Zhao Y, Xia J, Liu X, Xu JM, He B, Wu B, Zhang J (2017b) Asymmetric whole-cell bioreduction of sterically bulky 2-benzoylpyridine derivatives in aqueous hydrophilic ionic liquid media. Chem Eng J 316:919-927. https://doi.org/10.1016/j.cej.2017.02.028

Xu W, Jia H, Zhang L, Wang H, Tang H, Zhang L (2017c) Effects of GSH1 and GSH2 gene mutation on glutathione synthetases activity of Saccharomyces cerevisiae. Protein J 36:270-277. https://doi.org/10.1007/ s10930-017-9731-0

Yolmeh M, Khomeiri M (2017) Effect of mutagenesis treatment on antimicrobial and antioxidant activities of pigments extracted from Rhodotorula glutinis. Biocatal Agric Biotechnol 10:285-290. https://doi.org/10.1016/j. bcab.2017.04.007
Zeng W, Du G, Chen J, Li J, Zhou J (2015) A high-throughput screening procedure for enhancing alpha-ketoglutaric acid production in Yarrowia lipolytica by random mutagenesis. Process Biochem 50:1516-1522. https://doi.org/10.1016/j.procbio.2015.06.011

Zeng W, Fang F, Liu S, Du G, Chen J, Zhou J (2016) Comparative genomics analysis of a series of Yarrowia lipolytica WSH-Z06 mutants with varied capacity for a-ketoglutarate production. J Biotechnol 239:76-82. https:// doi.org/10.1016/j.jbiotec.2016.10.008

Zhang X, Zhang XF, Li HP, Wang LY, Zhang C, Xing XH, Bao CY (2014) Atmospheric and room temperature plasma (ARTP) as a new powerful mutagenesis tool. Appl Microbiol Biotechnol 98:5387-5396. https://doi. org/10.1007/s00253-014-5755-y

Zhang D, Wang Q, Liang X (2015a) Breeding high producers of enduracidin from Streptomyces fungicidicus by combination of various mutation treatments. Lect Notes Electr Eng 332:133-142. https://doi. org/10.1007/978-3-662-45657-6_14

Zhang G, Lin Y, Qi X, Wang L, He P, Wang Q, Ma Y (2015b) Genome shuffling of the nonconventional yeast Pichia anomala for improved sugar alcohol production. Microb Cell Fact 14:112. https://doi.org/10.1186/ s12934-015-0303-8

Zhang X, Zhang C, Zhou QQ, Zhang XF, Wang LY, Chang HB, Li HP, Oda Y, Xing XH (2015c) Quantitative evaluation of DNA damage and mutation rate by atmospheric and room-temperature plasma (ARTP) and conventional mutagenesis. Appl Microbiol Biotechnol 99:5639-5646. https://doi. org/10.1007/s00253-015-6678-y

Zhang C, Shen H, Zhang X, Yu X, Wang H, Xiao S, Wang J, Zhao ZK (2016) Combined mutagenesis of Rhodosporidium toruloides for improved production of carotenoids and lipids. Biotechnol Lett 38:1733-1738. https:// doi.org/10.1007/s10529-016-2148-6

Zheng Z, Cai C, Jiang T, Zhao M, Ouyang J (2014) Enhanced L-lactic acid production from biomass-derived xylose by a mutant Bacillus coagulans. Appl Biochem Biotechnol 173:1896-1906. https://doi.org/10.1007/ s12010-014-0975-2

Zhu L, Xu Q, Jiang L, Huang H, Li S (2014a) Polydiacetylene-based highthroughput screen for surfactin producing strains of Bacillus subtilis. PLoS ONE 9:e88207. https://doi.org/10.1371/journal.pone.0088207

Zhu P, Chen X, Li S, Xu H, Dong S, Xu Z, Zhang Y (2014b) Screening and characterization of Sphingomonas sp. mutant for welan gum biosynthesis at an elevated temperature. Bioprocess Biosyst Eng 37:1849-1858. https://doi. org/10.1007/s00449-014-1159-8

Zhu X, Arman B, Chu J, Wang Y, Zhuang Y (2017) Development of a method for efficient cost-effective screening of Aspergillus niger mutants having increased production of glucoamylase. Biotechnol Lett 39:739-744. https://doi.org/10.1007/s10529-017-2291-8

Zong H, Zhan Y, Li X, Peng L, Feng F, Li D (2012) A new mutation breeding method for Streptomyces albulus by an atmospheric and room temperature plasma. Afr J Microbiol Res 6:3154-3158. https://doi.org/10.5897/ AJMR11.1251

\section{Submit your manuscript to a SpringerOpen ${ }^{\circ}$ journal and benefit from:}

- Convenient online submission

- Rigorous peer review

- Open access: articles freely available online

- High visibility within the field

Retaining the copyright to your article

Submit your next manuscript at $\boldsymbol{\nabla}$ springeropen.com 